\title{
AS CONTRIBUIÇÕES DAS TECNOLOGIAS DIGITAIS DE INFORMAÇÃO E COMUNICAÇÃO NO ENSINO REMOTO DE BIOLOGIA
}

\author{
Laura Teresa Müller'; Carol Severo²; Ana Marli Bulegon³
}

\section{RESUMO}

A crise sanitária provocada pelo Covid-19, afetou diferentes vertentes da sociedade, em especial a área do ensino, levando a admissão do Ensino Remoto no país. Logo o uso das Tecnologias Digitais da Informação e Comunicação (TDIC), que antes estavam "batendo na porta" da educação, agora se tornaram essenciais para a retomada da educação. Nesse sentido, o presente trabalho tem como objetivo relatar duas vivências de prática docente, no contexto remoto, desenvolvidas no ano de 2020, na disciplina de Biologia, com o uso das TDIC, a fim de, verificar suas contribuições no processo de ensino e aprendizagem. Os resultados evidenciam que o uso das TDIC não dizima as possibilidades de ensino no contexto remoto. Essas, por outro lado, são capazes de desenvolver habilidades e competências. A atual condição não impede que o professor elabore aulas potencializadoras, reforçando a ideia de que o uso de TDIC enaltece muitas das estratégias didáticas.

Palavras-chave: Estratégias Didáticas; Aprendizagem Ativa; Ensino Remoto; Tecnologias Digitais.

Eixo Temático: Educação, Cultura e Comunicação (ECC).

\section{INTRODUÇÃO}

Os processos de globalização e comunicação, ancorados nas Tecnologias Digitais de Informação e Comunicação (TDIC), levaram o mundo ao encurtamento de distâncias geográficas, conectando diferentes povos em uma só rede, modificando a forma como as pessoas se relacionam e impactando, de forma direta, os processos culturais. A cultura digital provocou mudanças reais e significativas na

\footnotetext{
${ }^{1}$ Mestranda do Programa de Pós-graduação de Ensino de Ciências e Matemática (PPGECIMAT) da Universidade Franciscana (UFN) e bolsistas PROSUC CAPES. E-mail: I.muller@ufn.edu.br

${ }^{2}$ Mestranda do Programa de Pós-graduação de Ensino de Ciências e Matemática (PPGECIMAT) da Universidade Franciscana (UFN) e bolsistas PROSUC CAPES. E-mail: carol.severo@ufn.edu.br

3 Professora Doutora do Programa de Pós-graduação de Ensino de Ciências e Matemática (PPGECIMAT) da Universidade Franciscana (UFN). E-mail: anabulegon@ufn.edu.br
} 
EDUCAÇÃO, SAÚDE

ETECNOLOGIA

26 A 28 DE OUTUBRO DE 2021

sociedade, mas que até então, a dificuldade em perpassar os muros da escola era notável.

A pandemia causada pelo Covid-19 e o Ensino Remoto Emergencial imposto por tal, provocou um momento de efervescência na área do ensino, acelerando as mudanças necessárias que estavam "batendo na porta" da educação a tempos (MOTA, 2020). E assim como enfatizam as hipérboles, "em um piscar de olhos" e "do dia para noite", a tecnologia perpassou os muros da escola, adentrou ao contexto educacional e agora, somente através dela, os processos de ensino e aprendizagem poderiam continuar. Essa mudança rápida e emergencial, levou a suspensão de atividades letivas presenciais e obrigou professores e alunos a migrarem para a realidade on-line (MOREIRA, HENRIQUES e BARROS, 2020).

Nesse sentido, o presente trabalho tem como objetivo relatar duas vivências de Ensino Remoto, na disciplina de Biologia, com o uso das TDIC, a fim de, verificar suas contribuições no desenvolvimento de habilidades e competências, a partir das diferentes estratégias didáticas utilizadas no decorrer das aulas, como também diante das repercussões da interação dos alunos com as mesmas. Esse trabalho suscitou a partir de discussões e palestras da disciplina de Tópicos Especiais para o Ensino de Ciências e Matemática, do Mestrado Acadêmico em Ensino de Ciências e Matemática (PPGECIMAT), da Universidade Franciscana (UFN), em que ambas as autoras cursaram no primeiro semestre de 2021.

\section{MARCO TEÓRICO}

Nóvoa (2020, p. 9) cita que "No que diz respeito às TDIC, é evidente que elas fazem parte da cultura digital das sociedades contemporâneas e que seria absurdo que ficassem fora da escola e não fossem utilizadas do ponto de vista pedagógico".

No entanto, apesar das TDIC terem aberto caminhos para uma revolução na educação, "na maioria dos casos, estas tecnologias foram e estão sendo utilizadas numa perspectiva meramente instrumental, reduzindo as metodologias e as práticas a um ensino apenas transmissivo" (MOREIRA, HENRIQUES e BARROS, 2020, p. 352). Assim, ferramentas e recursos midiáticos, somente migraram do presencial para o virtual, substituindo o quadro e o giz, quando tais recursos poderiam ser 
melhor aproveitados se fossem exploradas suas reais potencialidades, facilitando os processos de mudança na educação (VALENTE, 2014).

As TDIC oferecem recursos de interatividade e facilidades comunicacionais que auxiliam os processos de construção do conhecimento. Dessa maneira, não é mais possível pensar a educação pautada em modelos de transmissão e repetição, de uma escola bancária, como já criticava Freire (1996). É preciso, aproveitar o que a tecnologia tem a oferecer, e de forma responsável e planejada, oportunizar caminhos pautados no desenvolvimento da autonomia e do protagonismo dos sujeitos. Levando a uma construção de conhecimento legítima, que faça relação aos conhecimentos prévios e a inter-relação com diferentes sujeitos, culturas e histórias, defendida por Vygotsky (1987).

Marcon, Silva e Erthal (2020, p. 93) afirmam que "Curiosamente a escola tenta omitir ou reprimir o uso das tecnologias, quando deveria fazer uso delas para motivar os estudantes, e levá-los a construção do conhecimento, aproveitando-se de suas leituras cotidianas". Respostas para questões como falta de interesse dos alunos pela aprendizagem e altos índices de abandono escolar, podem estar presentes na inserção de tecnologias digitais no contexto escolar, sendo aliadas no processo de inversão dessas questões. Uma vez que repercutem em uma aproximação do ambiente escolar ao cotidiano do aluno.

Dessa forma, os cenários educacionais têm de ser repensados e reinventados, onde suas práticas possam ir ao encontro dos anseios dos estudantes que estão imersos na tecnologia digital. Quando a escola entende esse processo, consegue cativar seus alunos e trabalhar múltiplos letramentos e desenvolver habilidades e competências, sejam eles, digitais, emocionais, sociais e cognitivos.

\section{METODOLOGIA}

O presente trabalho tem uma abordagem qualitativa, uma vez que, explora fenômenos em profundidade, procurando compreender aspectos subjetivos do cotidiano pesquisado, com enfoque na sua riqueza interpretativa e uso de uma reflexão contínua (MINAYO, 2001). Os dados foram coletados nos ambientes 
virtuais de interação e a partir das observações dos comportamentos e desempenhos dos alunos ao realizarem as atividades propostas.

As experiências aqui relatadas foram vivenciadas pelas autoras, mestrandas do PPGECIMAT-UFN, no Instituto Federal de Educação, Ciência e Tecnologia Farroupilha - Campus Santo Augusto, durante o período letivo do ano de 2020, em duas turmas distintas do curso Técnico Integrado em Alimentos. Uma responsável pela turma do primeiro ano (Turma 1A) e a outra pela do segundo ano (Turma 2A), ambas do Ensino Médio. Foram realizadas 20 horas/aula de regência e prática docente na disciplina de Biologia, diferenciando-se entre encontros síncronos e assíncronos, por adequação ao Ensino Remoto. A Turma 1A, possuía uma carga horária semanal de 3 horas/aula, dos quais dois deles seriam síncronos e um assíncrono. A Turma 2A, possuía uma carga horária semanal de 2 horas/aula, sendo a maioria dos encontros síncronos. $90 \%$ dos alunos dessas duas turmas possuía recursos tecnológicos e condições necessárias para o acompanhamento das aulas remotas em suas residências. Os encontros síncronos se deram através da plataforma Google Meet, e os assíncronos, por meio do e-mail institucional e grupos no aplicativo WhatsApp. Esse último como possibilidade de sanar dúvidas extraclasse de forma ágil.

\section{EXPERIÊNCIAS DE ENSINO REMOTO}

Nesta seção serão apresentadas as estratégias ditáticas utilizadas no decorrer das aulas remotas por ambas as autoras, que buscaram satisfazer as preocupações sobre proporcionar um ensino inovador e diferenciado através do uso das TDIC, que pudesse estimular os alunos a aprendizagem no âmbito do ensino remoto, mas que também oportunizasse uma construção de conhecimentos potencializadora e rica em significados.

\subsection{Relato de Experiência - Turma 1A}

Durante as 20 horas/aula de regência e prática docente, com a turma $1 \mathrm{~A}$, foi trabalhado o Módulo de Microbiologia, que incluíam os conteúdos de Vírus, Bactérias, Fungos e Protozoários. Visando um ensino e uma aprendizagem 
dinâmica e interativa, que proporcionasse estimular o protagonismo discente, foram adotadas diferentes estratégias didáticas no decorrer da experiência realizada.

Dentre elas, destacaram-se nos encontros síncronos: aulas expositiva dialogada, que fizesse referência ao cotidiano dos alunos e suas experiências de mundo; uso da experimentação como potencializadora de conceitos e estímulo ao pensamento crítico; uso de plataformas educacionais e jogos educacionais digitais, para retomar conceitos e conteúdos através de uma abordagem interativa; implementação de rodas de conversa para abordar doenças Virais, Bacterianas e Protozooses, de forma a estimular uma aprendizagem colaborativa e de trabalho em equipe; uso de exemplares para facilitar o entendimento dos assuntos, buscando levar o conteúdo mais perto do concreto.

Já, para os encontros assíncronos, destacaram-se: resolução de listas de questões de Enem e vestibulares, de forma a proporcionar uma autoavaliação da sua aprendizagem em Biologia; confecção de mapas mentais como forma de sistematização dos conteúdos; elaboração de relatórios de aula prática capazes de desenvolver uma análise reflexiva e pensamento crítico, através do exercício da escrita, juntamente com a elaboração de vídeos complementares; elaboração de vídeos e matérias sobre as doenças que seriam apresentadas nas rodas de conversa; atividade de campo (quintal de casa) em busca de exemplares fúngicos, capaz de desenvolver o espírito investigativo; uso de vídeos para aprofundar os assuntos vistos em aula, como também, alternativa para visualização de exemplares e espécies microscópicas.

A metodologia com aulas expositivas dialogadas, se fez presente durante os quatro conteúdos, envolvendo aspectos específicos de cada grupo, como também exemplos que relacionassem o cotidiano dos alunos, como quando falado sobre os vírus e a vivência da pandemia do Covid-19.

A experimentação ocorreu quando foi trabalhado o conteúdo de Bactérias, e através dela, pode-se inflamar o espírito científico e investigativo no âmbito da pesquisa. Trabalhou-se as características de crescimento microbiano, com materiais de fácil acesso, como gelatina incolor e caldo de carne. Nessa atividade, os alunos criaram um meio de cultura generalista e inocularam microrganismos de diferentes 
superfícies nesses meios. Posteriormente, realizaram o acompanhamento e observação do crescimento microbiano nos meios confeccionados. Como forma de registro e significação da prática, os alunos elaboraram um vídeo acompanhado da escrita de um relatório, descrevendo os materiais e o passo a passo do experimento, bem como a análise do crescimento microbiano e possíveis fatores relacionados a esse crescimento, estudados em aulas anteriores.

Para revisar e ressignificar os conceitos estudados, bem como para aguçar a curiosidade dos alunos, foram propostas rotinas de testes ao final de cada conteúdo, na plataforma educacional Kahoot, os quais chamamos de "BioQuiz". Nesses testes cada acerto permite o somatório de pontos, o que acaba desenvolvendo um espírito competitivo saudável aos alunos. Ao analisar os erros e acertos em cada questão é possível, ao próprio aluno, retomar o conteúdo, favorecendo a revisão e a identificação das dificuldades e fragilidades de compreensão e assimilação de um determinado conceito. Com isso, tal estratégia didática torna-se uma verdadeira aliada ao ensino, contribuindo principalmente no ensino remoto, para o desenvolvimento da autonomia e protagonismo dos alunos.

As rodas de conversa, adotadas em três momentos distintos, tiveram como objetivo discutir doenças humanas causadas por vírus, bactérias e protozoários. Nessa prática, a turma dividiu-se em duplas e cada grupo ficou responsável por pesquisar e elaborar uma apresentação de seus achados sobre uma doença em momento síncrono (pelo Google Meet), ou em forma de vídeo. Essa dinâmica de pesquisa ocorreu de forma síncrona (pelo Google Meet e Whatsapp) entre as duplas. A apresentação e discussão dos achados da pesquisa ocorreu de forma síncrona com toda a turma por meio do Google Meet. Muitos estudantes preferiram elaborar um vídeo para apresentar os resultados de suas pesquisas. Tal atividade proporcionou o desenvolvimento de habilidades e competências inerentes à cultura digital, na medida que ela proporcionou desafios de busca e compartilhamento de informações de forma remota e por meio das TDIC.

Para dar conta da complexidade sobre o ato de ensinar esses conteúdos foram desenvolvidas atividades práticas diversas, como por exemplo, a utilização de exemplares fúngicos, em aulas síncronas, bem como uma proposta de atividade de 
campo, denominada "Caça aos Fungos", em aula assíncrona, onde os alunos pudessem fotografar exemplares fúngicos no quintal de suas casas.

Todas as estratégias adotadas, nessa vivência, buscaram contribuir para tornar a aula dialógica e significativa, de forma que o ensino e aprendizagem de Biologia se mostrasse diferenciado e ativo. O andamento das aulas mostrou-se produtivo, uma vez que o comprometimento dos alunos foi exitoso com as atividades propostas e, para além disto, observou-se que as relações interpessoais foram sendo estreitadas e tornaram-se cada vez mais harmoniosas entre os envolvidos. $O$ desenvolvimento da Cultura Digital dos alunos e professores foi estimulado em todo o processo de ensino remoto aqui descrito, na medida em que todos tiveram a oportunidade de usar e vivenciar diferentes ferramentas midiáticas (Goolgle Meet, Aplicativo Whatsapp, Plataforma Kahoot, Plataforma Google, editores de vídeos, fotos e mapas mentais).

\subsection{Relato de Experiência - Turma 2A}

Ao ministrar aulas de Biologia no contexto de ensino remoto, na turma $2 \mathrm{~A}$, do curso Técnico em Alimentos, Integrado Ensino Médio, o uso das TDIC proporcionou diferentes experiências positivas, relacionadas às inúmeras possibilidades didáticas que puderam ser empregadas. As 20 horas/aula de regência organizaram-se entre nove encontros síncronos e, um encontro assíncrono, apresentando as seguintes temáticas de botânica: briófitas, pteridófitas, gimnospermas e angiospermas.

Para o estudo de ambos os quatro grupos vegetais, ocorreram aulas expositivas dialogadas (via Google Meet), auxiliadas por slides lúdicos, explicativos, enriquecidos por imagens, esquemas e animações. Durante as explicações dos mesmos, os alunos eram constantemente questionados, para assim, verificar seus conhecimentos prévios, resultando em interações consideráveis. Além disso, como forma de revisão do conteúdo estudado, ao final das aulas síncronas, eram propostos testes digitais, do tipo Quiz ("BioQuiz" - via Kahoot), onde a turma poderia responder questões de múltipla escolha e interagir com os colegas e a professora sobre suas respostas, via chat do Google Meet. Nesses momentos, havia bastante interação e questionamentos, referente às abordagens das questões. Nesse sentido, 
pôde-se perceber que atividades mais dinâmicas, despertavam uma maior participação e aproximação entre todos, naquele espaço virtual.

Como maneira de facilitar o entendimento, devido à complexidade acerca das questões evolutivas das plantas, utilizou-se uma analogia comparando a evolução desse reino de organismos, com a evolução tecnológica de aparelhos de comunicação (telefone, celular). Dessa forma, tentou-se relacionar o cotidiano dos alunos (uso da tecnologia) ao material de estudo. Tal estratégia analógica, também foi utilizada para viabilizar o estudo do ciclo reprodutivo de gimnospermas e angiospermas. Essa, por sua vez, envolveu a comparação com visitas entre amigos, o que também considerou o cotidiano dos alunos. Através da câmera da professora pelo Google Meet, foi possível mostrar esses materiais, situando cada estrutura, trazendo assim, uma certa ludicidade para a dinâmica dos ciclos de vida dos musgos, samambaias, estruturas reprodutivas de gimnospermas (pinhas) e estrutura da flor. Materiais naturais, como musgos, folhas de samambaias, estróbilos femininos e masculinos (pinhas), pinhões e flores, também auxiliaram muitas das explanações, permitindo aos alunos uma visão real dentro de cada grupo estudado.

Em relação ao estudo das briófitas e pteridófitas, foi solicitado aos alunos, que realizassem investigações, nas quais deveriam observar, no local onde residem, em quais condições essas musgos e samambaias se encontram (em locais de luminosidade, umidade, observando suas estruturas reprodutivas evidentes, por exemplo).

Para sistematização do conteúdo (diferenças/semelhanças entre os quatro grupos vegetais) for realizada uma aula prática de comparação entre monocotiledôneas e eudicotiledôneas. Como estretégia de avaliação foi proposto que os alunos elaborassem esquemas/mapas mentais (via Plataformas e aplicativos digitais), os quais foram desenvolvidos de forma criativa no qual todos os assuntos estudados foram contemplados. O encontro em que foi realizada a aula prática, configurou-se bastante interativo e dinâmico. Durante as comparações, entre folhas, caules, raízes e flores, os alunos participavam via áudio e também pelo chat, destacando conhecimentos acerca do assunto, assim como, respondendo às questões realizadas durante a comparação entre os materiais. Esses (folhas, flores, 
etc...) eram nitidamente mostrados, facilitando a diferenciação entre cada estrutura. Assim, os alunos conseguiam comparar, analisar e desenhar os tipos de materiais analisados e compará-los, tornando a aprendizagem significativa.

\section{CONTRIBUIÇÕES DAS TDIC PARA O ENSINO REMOTO DE BIOLOGIA}

A partir desse conjunto de ações que foram desenvolvidas em ambas às 20 horas/aulas de Biologia, evidencia-se que a recorrência às TDIC não dizima as possibilidades de ensino no contexto remoto. Essas, por outro lado, são capazes de promover interação, pesquisa e investigação numa perspectiva mais autônoma e protagonista do aluno. A atual condição não impede que o professor elabore aulas potencializadoras, reforçando a ideia de que o uso de TDIC enaltece muitas das estratégias e metodologias didáticas.

As aulas com a inserção de jogos educacionais digitais e testes do tipo Quiz, para retomar o conteúdo e conceitos vistos anteriormente, aparentemente despertaram a interação e colaboração entre os sujeitos em ambas as experiências. De acordo com Ramos (2009) os jogos educacionais digitais, permitem a integração entre aspectos cognitivos, sociais e digitais. Os aspectos cognitivos se relacionam com o uso de conceitos complexos estimulando novas aprendizagens. Os sociais podem ser visualizados nas interações entre os sujeitos que o jogo desperta. $E$ os digitais na vivência e aprendizagem com novas ferramentas midiáticas.

Aulas com o uso da experimentação e atividades de exploração do ambiente natural, buscaram desenvolver um espírito investigativo e crítico nos alunos. Silva e Ramos (2013) enfatizam que colocar o aluno em situação de experimentação significa deixá-lo questionar o seu conhecimento e o objeto que lhe é mostrado.

As aulas com o uso de modelos didáticos, exemplares naturais e analogias buscaram amenizar a complexidade dos conceitos, trazendo os conteúdos mais perto da realidade concreta, além de relacionar o material de estudo a aspectos do cotidiano. Delizoicov, Angotti e Pernambuco (2011) salientam que o aluno é portador de saberes e experiências que adquire constantemente em suas vivências, e ao trazer o mundo externo para o ambiente escolar, o professor possibilita o acesso a novas formas de compreendê-lo. 
A partir disso, acredita-se que aulas expositivas dialogadas, amparadas por táticas diversificadas, potencializam o ambiente virtual de ensino, articulado através das TDIC. Esse espaço também favoreceu a promoção de rodas de conversa e questionamentos para verificar os conhecimentos prévios, além de atividades de pesquisa que visaram a troca de saberes e o trabalho em equipe. Essa consideração dos conhecimentos previamente construídos pelos alunos apresentase indispensável, pois, é notório que o senso comum também adentra o espaço escolar de forma natural e inevitável. Sendo assim, a sondagem dos conhecimentos prévios propicia um novo entendimento do mundo em que se vive, através da desestruturação dos mesmos (DELIZOICOV, ANGOTTI, PERNAMBUCO, 2011, p. 153).

Em diferentes momentos foi oportunizado a interação dos alunos com diferentes TDIC. O contato entre professor e aluno se deu por meio da Plataforma Google (Google Meet, Gmail e Google Drive) e do aplicativo de Whatsapp como Ambiente Virtual de Aprendizagem (AVA). Além desses, fez-se uso de sites e aplicativos de construção de mapas mentais, edição de imagens e vídeos e criação de materiais de apresentação, como o uso do Canva, Cmaptools, entre outros, foram incorporados ao processo de ensino remoto. O uso dessas tecnologias aproximou o processo da aprendizagem com ao cotidiano dos alunos, uma vez que, esses já nasceram inseridos na cultural digital (PRENSKY, 2012).

O ensino remoto demandou que professores e alunos migrassem "para a realidade on-line, transferindo e transpondo metodologias e práticas pedagógicas típicas dos territórios físicos de aprendizagem" (MOREIRA; SCHLEMMER 2020, p. 07). A noção de mera transferência e transposição ao estilo das práticas presenciais faz com que se tenha que considerar que a tecnologia por si só "não muda as práticas pedagógicas" (MOREIRA; SCHLEMMER, 2020, p. 06), o que implica em repensar práticas educativas que sustentem um conhecimento coletivo e uma aprendizagem colaborativa. Assim, espera-se que as aulas remotas devam ir além da mera adoção de aplicativos e softwares, que permitam não apenas a transposição do conteúdo em livros e cadernos, mas que fomentem o engajamento nas atividades didáticas. 
Nesse sentido, o uso das TDIC na perspectiva do ensino remoto, aparentemente fomentaram o desenvolvimento de competências no processo de ensino e aprendizagem de Biologia, uma vez que, em diferentes momentos foi trabalhada habilidades digitais, sociais, cognitivas e emocionais.

\section{CONSIDERAÇÕES FINAIS}

O presente trabalho buscou relatar duas vivências de Ensino Remoto, na disciplina de Biologia, em uma escola federal no município de Santo Augusto, Rio Grande do Sul. Para fomentar o processo de ensino e aprendizagem foram adotadas diferentes estratégias didáticas que fizessem referência às TDIC. A dinâmica proposta nas atividades extrapolou os muros escolares e favoreceu 0 estudo para além do tempo e espaço destinado ao momento aula. Isso permitiu o desenvolvimento da autonomia, protagonismo, cidadania e de habilidades e competências, inerentes ao uso das TDIC e próprias da Cultura Digital. Habilidades essas do tipo cognitivas, relacionadas aos processos de integração de conceitos e argumentação; sociais, relacionadas ao trabalho em equipe e a colaboração entre os sujeitos; emocional, relacionadas a motivação e a satisfação em aprender; digitais, relacionadas as vivências com diferentes tecnologias adotadas durante as práticas docente.

Dessa forma, é possível refletir sobre a importância do ensino remoto na inclusão do uso das TDIC na educação e o desenvolvimento da cultura digital, tanto de alunos como de professores. Nesse contexto, a formação continuada de professores, para o uso das TDIC, e a estrutura tecnológica, no âmbito das escolas, é algo que precisa ser pensado. O uso das TDIC não requer o abandono do caderno e lápis, mas permite a aproximação da realidade do aluno ao ambiente escolar. Isso potencializa o ensino e fomenta a aprendizagem em qualquer tempo e espaço.

\section{AGRADECIMENTOS}

O presente trabalho foi realizado com apoio da Coordenação de Aperfeiçoamento de Pessoal de Nível Superior - Brasil (CAPES) - Código de Financiamento 001. 


\section{REFERÊNCIAS}

DELIZOICOV, D.; ANGOTTI, J. A.; PERNAMBUCO, M. M. Ensino de ciências fundamentos e métodos. 4. ed. São Paulo: Cortez, 2011.

FREIRE, P. Pedagogia da autonomia: saberes necessários à prática educativa. 25. ed. São Paulo: Paz e Terra, 1996.

MARCON, V. da S.; SILVA, V. C. da; ERTHAL, A. Experiências de multiletramento na escola pública: ensino híbrido, metodologias ativas e interdisciplinaridade. Revista Prâksis, a. 17, n. 2, 2020.

MINAYO, M. C. de S. Pesquisa Social. Teoria, método e criatividade. 18 ed. Petrópolis: Vozes, 2001.

MOREIRA, J. A. M.; HENRIQUES, S.; BARROS, D. Transitando de um ensino remoto emergencial para uma educação digital em rede, em tempos de pandemia. Revista DIALOGIA, n. 34, 2020, p. 351-364.

MOREIRA, J. A.; SCHLEMMER, E. Por um novo conceito e paradigma de educação digital online. Revista UFG, v. 20, 2020.

NÓVOA, A. A pandemia de Covid-19 e o futuro da Educação. Revista Com Censo: Estudos Educacionais do Distrito Federal, v. 7, n. 3, p. 8-12, ago. 2020. Disponível em: http://www.periodicos.se.df.gov.br/index.php/comcenso/article/view/905. Acesso em: 16 de jul. 2021.

NÓVOA, A.; MOTA, R. Docência em tempos de pandemia. Youtube, 16 abri. 2020. Disponível em: https://farol.ufsm.br/video/gravacao-da-web-conferencia-docenciaem-tempos-de-pandemia. Acesso em: 16 de jul. 2021.

PRENSKY, M. Aprendizagem baseada em jogos educacionais digitais. São Paulo: Senac, 2012.

RAMOS, D. K. A formação de professores para o uso das tecnologias: um mosaico de concepções e emoções. Novas tecnologias na Educação, v. 7, n. 1, 2009.

SILVA, A. de H. L.; RAMOS, Z. F. Contextualizando o processo de ensino aprendizagem de Botânica. Curitiba: Ed. Prismas, 2013.

VALENTE, J. A. A comunicação e a educação baseada no uso das tecnologias digitais de informação e comunicação. Revista UNIFESO - Humanas e Sociais, v. 1, n. 1, 2014, p. 141-166.

VYGOTSKY, Lev. Pensamento e Linguagem. Tradução de Jefferson L. Camargo. São Paulo: Martins Fontes, 1987. 